\section{Cumbre Iberoamericana de Jefes de Estado y Presidentes de Gobierno: Declaración de Viña del Mar ${ }^{1}$}

Basado en la "Declaración de Viña del Mar" y otros documentos pertinentes aprobados en la VI Cumbre Iberoamericana celebrada en Viña del Mar, Chile, del 10 al 11 de noviembre de 1996.
Los días 10 y 11 de noviembre de 1996 se realizó en Santiago y Viña del Mar, Chile, la VI Cumbre Iberoamericana de Jefes de Estado y Presidentes de Gobierno, encuentro que confirmó y realzó los principios y objetivos de las Cumbres anteriores, con las que se ha logrado crear un espacio de concertación y cooperación para impulsar el desarrollo de la comunidad de naciones iberoamericana. Los Jefes de Estado y de Gobierno de 21 países iberoamericanos aprobaron la "Declaración de Viña del Mar", en la que reiteraron su compromiso con los principios de democracia, estado de derecho y pluralismo político. Declararon asimismo su respeto a las libertades fundamentales y derechos humanos, al derecho internacional y a la Carta de las Naciones Unidas. Sobre todo, hicieron hincapié en los principios de soberanía, no intervención e igualdad jurídica de los Estados, así como en el privilegio que tiene cada pueblo para edificar libremente en paz, estabilidad y justicia, su propio sistema político e institucional.

En la quinta Cumbre, que se llevó a cabo en Bariloche (Argentina) en octubre de 1995, se habían determinado los grandes desafíos que América Latina enfrenta en los umbrales del siglo XXI: la promoción y consolidación de un desarrollo social y económico sostenible; la profundización, ampliación y fortalecimiento de la integración regional; y la inserción de los países latinoamericanos en un mundo en profunda transformación tecnológica y productiva. Además de estas grandes tareas, cada vez se perfila con mayor importancia la necesidad de atender al desarrollo político como condición básica para asimilar los cambios de escala global y participar en ellos de forma provechosa. En este contexto es imprescindible afianzar la robustez de las democracias de la Región y el tema fue uno de los más importantes que se trató en la sexta Cumbre.

\section{GOBERNABILIDAD \\ PARA UNA DEMOCRACIA EFICIENTE Y PARTICIPATORIA}

Los pueblos latinoamericanos sostienen que la independencia y el control mutuo de los poderes; la representación y participación de mayorías y minorías; las libertades de expresión, asociación y reunión; el pleno acceso a la información, y las elecciones libres y transparentes constituyen elementos esenciales de una democracia. La consolidación de 
esta forma de gobierno es, por lo tanto, una tarea constante e insoslayable de cada pueblo. La participación efectiva de la población en el debate de la vida pública fortalece a la sociedad y presupone transformaciones económicas y culturales que lleven a disminuir las desigualdades y exclusión sociales. En este sentido, cada Estado tiene una función trascendental.

Al mismo tiempo que se atiende a la eliminación de la pobreza y al mejoramiento de la seguridad pública y la administración de la justicia, es preciso intensificar la lucha contra el mercadeo ilícito de drogas, la corrupción y el terrorismo, tres elementos que a menudo están relacionados. Esos esfuerzos, así como la lucha contra el lavado de dinero y el tráfico de armas, requieren el fortalecimiento de los lazos entre naciones. En consecuencia, dentro de las legislaciones respectivas, tienen que incluirse mecanismos de cooperación policial y judicial para llevar a los responsables a la justicia y hacer que cumplan las penas impuestas. Puesto que ya existen intercambios institucionales, es muy posible cooperar de forma eficaz en este campo.

\section{CONDICIONES INTERNACIONALES DE COOPERACIÓN PARA LA DEMOCRACIA}

Para lograr la cooperación política en las Américas, es fundamental respetar estrictamente la soberanía, integridad territorial y autodeterminación de cada país, según sus tradiciones nacionales. Este criterio, desarrollado en Cumbres anteriores, repudia cualquier intento dirigido a alterar el orden institucional dentro de cualquier nación. Se han establecido mecanismos de consulta para casos de urgencia o relevancia especial, los cuales han permitido proteger con éxito los valores democráticos y de soberanía.

Así como la democracia garantiza y contribuye a las relaciones pacíficas entre los pueblos, la capacidad para gobernar democráticamente se fortalece en un entorno de paz y seguridad internacionales. Por otra parte, es necesario comprender cabalmente el proceso de globalización que impera hoy en día, con sus riesgos y oportunidades. Este ha llegado a convertirse en una característica de la sociedad contemporánea, que afecta a la vida de las poblaciones y a las acciones de los gobiernos. Con objeto de integrar a los países de la Región en un sistema económico interdependiente y progresivamente más globalizado, se ha impulsado la liberalización de intercambios comerciales dentro de la Región y a nivel mundial. La Cumbre se pronunció en contra de cualquier medida contraria al libre comercio y destacó que el desarrollo binacional y subregional de transportes y comunicaciones faci- lita el intercambio no solo económico, sino social y cultural.

\section{DIMENSIONES SOCIALES, ECONÓMICAS Y POLÍTICAS}

Evidentemente la estabilidad democrática y el desarrollo económico y social van de la mano, pero las prácticas de gobierno inadecuadas han agravado los problemas sociales en muchos países. En la reunión, por lo tanto, se plantearon los temas de la equidad y de igualdad de oportunidades para hombres y mujeres, responsabilidades tanto del gobierno como del sector privado. Se instó a llevar a cabo un vasto intercambio de ideas y experiencias sobre la inversión social, generación de empleos, modernización tecnológica y otros asuntos de política social. Se insistió igualmente en la importancia de que todos los habitantes participen y sean representados en una democracia, sin distinción de raza, religión o sexo y con especial consideración de las poblaciones indígenas. Se reconoció el pleno derecho de las comunidades autóctonas al desarrollo político, económico, social y cultural.

Uno de los mayores logros históricos ha sido el paso de una política basada en el conflicto a una sustentada en la cooperación. La búsqueda de acuerdos se ha convertido en una práctica corriente, incluso en el campo laboral y empresarial. Debe afianzarse hondamente en la cultura democrática que los derechos fundamentales de todo ciudadano deben estar a salvo de ser afectados por cualquier visión dogmática del Estado o la sociedad.

\section{COOPERACIÓN DERIVADA DE LAS CUMBRES}

Se recordó que en la Cumbre de Bariloche se había instituido un sistema de cooperación para el desarrollo, pero que ahora los países debían movilizar los recursos humanos y financieros para que los programas tuvieran los resultados esperados. En diciembre de 1996 entró en vigencia el Convenio para la Cooperación en el Marco de la Conferencia Iberoamericana, pero ya se estaban obteniendo resultados importantes con varios programas en ejecución antes de esa fecha.

Se mencionaron los siguientes programas exitosos: Alfabetización y Educación Básica de Adultos; Cooperación en el Desarrollo de Programas de Doctorado y en la Dirección de Tesis Doctorales; Centro Iberoamericano de Desarrollo Estratégico Urbano; y Cooperación Científica y Tecnológica. Se acogió con entusiasmo la iniciativa de un fondo para asegurar las actividades del Programa de 
Desarrollo de los Pueblos Indígenas y las de la Televisión Educativa, a cuyo financiamiento se estaban incorporando varios países. A raíz de la VI Cumbre, se anunció la puesta en marcha inmediata de otros programas originados en la Cumbre de Bariloche: Desarrollo de Sistemas Nacionales de Educación, Evaluación de la Calidad Educativa, Diseño de la Formación Profesional y Modernización de los Administradores de la Educación.

Teniendo en cuenta el doble objetivo de difundir la cultura y fomentar la industria y el mercado iberoamericano de medios audiovisuales, se apoyó la iniciativa de un Programa de Desarrollo Audiovisual en Apoyo de la Construcción del Espacio Visual Iberoamericano. Se respaldó asimismo la creación de un espacio común para el libro iberoamericano con intervención de los sectores estatal y privado y de organismos regionales, para lo cual será esencial contar con un repertorio del Sistema Internacional de Notación de Libros (ISBN) en español y portugués.

Entre los proyectos vigentes dignos de mención se destacó el de interconexión eléctrica centroamericana, especialmente porque favorece la integración subregional. También se acogió con beneplácito la iniciativa de Chile de crear un Fondo Interamericano de Integración Científica y Tecnológica, tema que se considera de prioridad y en virtud de lo cual se instó a dicho país a avanzar en el proyecto. Se recomendó además la creación de una Red Iberoamericana de Gobernabilidad como instrumento para el intercambio de experiencias nacionales sobre ese tema.

A la secretaría pro témpore se encomendó una serie de tareas que incluyen elaborar un informe sobre los programas, proyectos e iniciativas de cooperación iberoamericana; crear y mantener actualizada, para distribución a los países miembros, una base de datos sobre las decisiones, situación de convenios y programas, personas responsables de tareas y documentos emanados de cada Cumbre; y encargarse de notificar a los países y coordinar la distribución de información y otras actividades preparatorias para futuras Cumbres. Por cierto, se anunció que había entrado en funcionamiento un Comité de Alto Nivel engargado de proponer un cronograma de trabajo y de promover estudios sobre la constitución de la Comunidad Latinoamericana de Naciones y su vinculación con la Comunidad Iberoamericana.

\section{ASUNTOS DE ESPECIAL INTERÉS}

Entre los asuntos que se hicieron notar al pleno por su interés especial figuran los siguientes:
Se respaldaron enérgicamente los esfuerzos del Gobierno y de la Unidad Revolucionaria Nacional Guatemalteca para dar fin al enfrentamiento armado y suscribir acuerdos que garanticen una paz firme y duradera. Se reconoció con aprecio especial el papel que en ello desempeñaron las Naciones Unidas y el Grupo de Amigos de Guatemala.

También se tomó nota de la "Declaración de Antigua, Guatemala, sobre Derechos Humanos y Cultura de Paz" aprobada durante la reunión del Foro Iberoamericano de Ombudsmen en esa ciudad en junio de 1996.

Fueron motivo de encomio no solo las elecciones recientes llevadas a cabo en Nicaragua, ya que constituyeron un elemento básico para la democracia en Centroamérica, sino también el Gobierno de esa nación por su labor en busca de la paz, la democratización y la reconciliación nacional. Se formularon votos por que el presidente electo continúe por la misma senda.

Se recordó que durante la Conferencia de las Naciones Unidas sobre el Medio Ambiente y el Desarrollo celebrada en Rio de Janeiro en 1992 se habían establecido los principios de lo que se debe entender por desarrollo sostenible. Se hizo un llamado a los organismos internacionales a que participaran en la conferencia sobre el mismo tema que se había de realizar en Bolivia en diciembre de 1996. En otra dirección afín, los presentes afirmaron su determinación de luchar contra la pobreza, la desnutrición, la marginación social y el analfabetismo mediante la adopción de políticas de mediano plazo. Estas se relacionan con estimular las empresas pequeñas y medianas, crear empleos mejor remunerados, mejorar la instrucción y capacitar al sector laboral. Para avanzar hacia estas metas, se consideró necesario conseguir también mayor apoyo de los organismos internacionales. Como tema de interés especial, la Cumbre apoyó el diálogo de alto nivel dirigido a fortalecer la estrategia competitiva de las empresas pequeñas y medianas mediante la articulación de diversos sectores, incluso el gubernamental.

Dada la importancia de impulsar la ya existente Alianza para la Lucha contra las Drogas, se ratificó el compromiso de cooperar contra el consumo, la producción y el tráfico de narcóticos. La complejidad del problema exige que la responsabilidad se comparta, pero con respeto a la soberanía de los Estados. Entre las acciones comunes por emprender se mencionaron combatir el lavado de activos, mejorar el control del comercio de precursores o reactivos químicos esenciales y del tráfico de armas y materiales explosivos, profundizar en las políticas de desarrollo alternativo para asegurar el bienestar de las comunidades afectadas y aprove- 
char el papel que desempeña la educación en contra del consumo de drogas. Se apoyó el proyecto de celebrar en 1998 sesiones extraordinarias para tratar ese acuciante problema.

Se destacó el resultado de la reciente Conferencia Internacional sobre el Terrorismo, al mismo tiempo que se condenó ese flagelo en todas su formas y se reiteró el compromiso de luchar por extirparlo. En el campo de las cuestiones jurídicas, comerciales y humanitarias, se confirmó el deseo de contribuir a codificar el derecho internacional. El conocimiento de ese derecho cobra cada día más importancia por los cambios profundos que ha ocasionado el recrudecimiento de antiguos conflictos y violencia entre ciertos países. Se manifestó preocupación por los obstáculos que hacen peligrar la paz en el Oriente Medio y se hicieron votos por que los problemas que afectan a toda esa región, y especialmente a Jerusalén, sean resueltos con garantía de acceso a los Santos Lugares y con respeto al derecho internacional.

En las Américas, se rechazó decididamente la aplicación de medidas punitivas unilaterales que afecten al comercio internacional y al bienestar de los pueblos iberoamericanos. Por lo tanto, se recusó la Ley Helms-Burton de los Estados Unidos de América, aduciéndose que viola la Carta de las Naciones Unidas, menoscaba la amistad y cooperación que deben existir en las relaciones internacionales y que significa una aplicación extraterritorial del derecho interno. Se destacó al respecto la opinión unánime del Comité Jurídico Interamericano de la Organización de los Estados Americanos (OEA). En el contexto de las normas y principios del derecho internacional y tal como se había afirmado en las tres cumbres anteriores, se continuó suscribiendo la gestión del Secretario de las Naciones Unidas para hallar una solución justa y universalmente aceptable a la cuestión de Timor Oriental.

En lo que se refiere a medidas de seguridad, se respaldó ampliar y perseverar en el diálogo regional sobre la seguridad hemisférica en un ambiente de cooperación y entendimiento. Hubo interés en el Tratado Marco de Seguridad Democrática en Centroamérica, que establece un modelo de seguridad regional con el desarrollo humano como eje fundamental. Se mostró satisfacción por la creación, en julio de 1996, de la Asociación Iberoamericana de Organismos de Protección y Defensa Civil.

Fue bien recibida la noticia de que habían entrado en la Conferencia de Desarme, único foro multilateral que busca negociar en esa materia, varios países latinoamericanos. Se reforzó el compromiso de lograr, a la mayor brevedad posible, la prohibición de ensayos nucleares aprobada por las Naciones Unidas. Es opinión consultiva de la Corte
Internacional de Justicia de julio de 1996, que la amenaza de las armas nucleares se opone a las reglas del derecho internacional y que el desarme debe llevarse a cabo de buena fe en todos sus aspectos. Por lo tanto, es de desear su pronta y plena vigencia en América Latina y el Caribe, como ejemplo para otras zonas del mundo. También se subrayó la importancia de la iniciativa de la OEA de declarar a las Américas zona libre de minas terrestres antipersonales y se exhortó a la comunidad internacional a hacerlas desaparecer antes del año 2000, para lo cual dicho organismo requiere apoyo financiero.

En lo que respecta al tráfico ilícito de armas, se acogió lo adoptado por la Comisión de Desarme de las Naciones Unidas sobre las transferencias internacionales de armas, al efecto de que estas no deben usarse para intervenir en los asuntos internos de los países.

Se expresó satisfacción por haberse cumplido el décimo aniversario de dos acontecimientos importantes: el de la formación del Grupo de Río y el del Acuerdo de Esquipulas. Ambos han promovido los derechos humanos y procesos de integración y cooperación, reconciliación por medio del diálogo y la democracia.

Por otra parte, siendo el quincuagésimo aniversario de la UNESCO, la Cumbre reiteró su compromiso con los ideales de paz, justicia, libertad y solidaridad y declaró que seguirá alentando el trabajo conjunto entre países en todas las ramas de la actividad intelectual. Declaró necesario, como medio para exaltar los sentimientos de solidaridad entre las naciones, llevar adelante la visión compartida de la historia de América Latina. Rechazó enérgicamente la falsificación, el plagio o la reproducción ilícita de obras y publicaciones y se manifestó a favor del régimen general de protección de los derechos de autor. Asimismo reafirmó su voluntad de asegurar la más amplia difusión y enseñanza del español y el portugués. En consecuencia, recibió entusiasta aprobación el Congreso Internacional de Lengua Española que se proyectaba celebrar en Zacatecas, México, como forma de abrir caminos al enriquecimiento y la difusión de la lengua. Mereció aplausos la creación de la Comunidad de Países de Lengua Portuguesa, con la cual se esperaba mantener muy estrechas relaciones. Se reconoció igualmente el desarrollo de la Asociación de Bibliotecas Nacionales de Iberoamérica (ABINIA) fundada en México en 1989, y de su programa destinado a unificar el trabajo de las bibliotecas miembros, en la tarea de preservar el patrimonio gráfico y documental de los países.

En vista de los lazos históricos y culturales que unen a las Américas con África, se tomó nota 
con interés de la propuesta formulada por Portugal a sus socios de la Unión Europea para realizar una Cumbre Europa-África. Esta se dirigiría a contribuir al diálogo político para crear las condiciones que permitan un progreso socioeconómico efectivo del continente africano.

Teniendo en cuenta el peso considerable que la deuda externa significa para los países, se dio el visto bueno a los procesos de renegociación. Al mismo tiempo, se hizo un llamado a los acreedores acerca de la posibilidad de brindar facilidades para el cumplimiento de esos compromisos financieros sin descuidar los programas de desarrollo social, tan necesarios para consolidar la democracia.

Se mencionó como motivo de complacencia la Cumbre Mundial de la Alimentación convocada por la Organización de las Naciones Unidas para la Agricultura y la Alimentación (FAO). Esta, con su finalidad de renovar el compromiso de la comunidad internacional para erradicar el hambre, inspiró la voluntad de contribuir a su éxito.

Antes de dar fin al encuentro se anunciaron las próximas Cumbres Iberoamericanas, que tendrán lugar en Venezuela (1997), Portugal (1998), Cuba (1999), Panamá (2000) y Perú (2001). Se acogió con gusto el ofrecimiento de la República Dominicana de servir de anfitriona para la Cumbre de 2002.

\section{SYNOPSIS}

\section{Ibero-American Summit of Heads of State and Government: Declaration of Viña del Mar}

The leaders of 21 Ibero-American countries came to Viña del Mar (Chile) for the sixth meeting of the now-traditional Ibero-American Summits. The Declaration that resulted from the Summit reiterated the commitment of these nations to the principles of democracy, the rule of law, and political pluralism. The development of efficient and participatory systems of democratic government was one of the most important of the topics dealt with at the meeting and served as the framework for the discussion and the search for solutions to common problems, such as poverty, arms trafficking, unequal opportunity for men and women, and inappropriate government practices. The leaders also supported a series of initiatives and international programs in the technological and cultural arenas that will strengthen the ties and unite the Spanish-and Portuguese-speaking countries.

\section{ERRATA}

Borda y Rea, "Susceptibilidad de Biomphalaria tenagophila de las cuencas de los ríos Paraná y Uruguay a Schistosoma mansoni" (Rev Panam Salud Publica/Pan American Journal of Public Health 1997;1(3):167-173)

Los autores han solicitado las siguientes correcciones:

- P. 169, cuadro 1: En el rubro correspondiente a Encarnación, Departamento de Itapúa, Paraguay, la cepa de Schistosoma mansoni utilizada debe ser BH2 en vez de SJ2.

- P. 170: La primera oración de la sección de "Resultados" debe decir "Fueron expuestos a miracidios de $S$. mansoni un total de 1711 ejemplares de B. tenagophila: 668 a la cepa SJ, 400 a la SJ2 y 643 a la BH2" 